\title{
Transseptal pressure gradient with leftward septal displacement during the Mueller manoeuvre in $\operatorname{man}^{\star} \dagger$
}

\author{
PABLO A GUZMAN, W LOWELL MAUGHAN, FRANK C P YIN, LELAND W EATON, \\ JEFFREY A BRINKER, MYRON L WEISFELDT, JAMES L WEISS
}

From Cardiology Division, Department of Medicine, The fohns Hopkins Medical Institutions, Baltimore, Maryland, USA

SUMMARY Septal displacement is postulated as an important mediator of ventricular interdependence. During acute right ventricular loading with the Mueller manoeuvre the septum flattens and shifts leftward. To investigate the mechanism of this septal deformation, we measured transseptal pressures in nine patients during Mueller manoeuvres with simultaneous right and left ventricular micromanometers, and left ventricular configuration with two-dimensional echocardiograms. Data were analysed throughout diastole and at end-systole during control and maximum Mueller manoeuvre ( -40 to $-80 \mathrm{mmHg}$ airway pressure). Leftward septal displacement during the Mueller manoeuvre was evidenced by an increase in septal radius of curvature at end-diastole persisting through end-systole. The left ventricular free wall radius of curvature was unchanged. During the Mueller maneouvre, the left ventricular cavity area decreased significantly in the cross-sectional view. All Mueller manoeuvres were associated with a decrease in left-to-right ventricular transseptal pressure gradient throughout diastole. There was no significant change in the gradient at end-systole; septal flattening persisted, however, despite a pronounced left to right pressure gradient. Thus, diastolic septal flattening during right ventricular loading is associated with a decreased transseptal pressure gradient but does not require right ventricular diastolic pressure to exceed left ventricular diastolic pressure. The persistence of flattening in systole suggests that once septal shift occurs during diastole, other forces during systole maintain the deformity despite a large intracavitary transseptal gradient.

Acute left ventricular diastolic pressure-volume shifts have been observed in a variety of conditions including vasodilator infusion, ${ }^{1-3}$ vasoconstrictor infusion, ${ }^{3}$ and right ventricular pressure and/or volume loading. ${ }^{4-8}$ Mechanisms suggested to explain these shifts include the phenomenon of incomplete relaxation, ${ }^{10}$ changes in the passive elastic properties of the ventricular chamber, ${ }^{9} 10$ changes in coronary blood supply, ${ }^{9}$ and changes in the external restraints on the left ventricle. ${ }^{19-16}$ The phenomenon whereby the function of one ventricle is altered by changes in the filling of the other has been referred to as ventricular interdependence. ${ }^{14711}$ Since the right

* Supported by USPHS Grants and Ischemic Heart Disease SCOR, from the National Heart, Lung and Blood Institute, National Institutes of Health, Bethesda, Maryland.

+ Presented in part at the 52nd Annual Scientific Sessions of the American Heart Association in Anaheim, California, November 1979.

Received for publication 1 September 1981 and left ventricles share a common interventricular septum it seems likely that alterations in configuration or position of the septum may alter the performance or geometry of either ventricle. Previous studies in both experimental animals and man have shown alterations in septal configuration or position during acute ventricular loading. ${ }^{7817}$ The mechanism for septal displacement during acute right ventricular loading, however, is unclear.

The goal of the present study was to investigate the mechanism of leftward septal displacement during the Mueller manoeuvre (forced inspiration against a closed airway) by correlating this with changes in transseptal pressures. In patients undergoing cardiac catheterisation we measured right and left ventricular pressures with micromanometer catheters during the Mueller manoeuvre, while simultaneously determining left ventricular and septal geometry by twodimensional echocardiography. 


\section{Subjects and methods}

Nine patients undergoing routine cardiac catheterisation at the the Johns Hopkins Hospital Cardiovascular Diagnostic Laboratory were studied. Before catheterisation, informed consent was obtained and the patients were taught to perform the Mueller manoeuvre beginning at functional residual capacity (FRC). Four patients had chest pain with normal coronary arteries, and five had coronary artery disease. All had ejection fractions greater than $50 \%$. None had segmental dysfunction involving the interventricular septum. Two patients with coronary artery disease had hypokinesis of the inferior and one of the anterior wall.

Left ventricular pressure was measured with a micromanometer-tipped catheter (Millar model No. 471 ) inserted through a sheath (Cordis) in the femoral artery. Right ventricular pressure was measured with a second micromanometer-tipped catheter inserted through an antecubital vein. To minimise baseline drift, the catheters were soaked in saline soution at $37^{\circ} \mathrm{C}$ for at least three hours. They were calibrated initially with an electrical calibration signal and at the completion of the study both electrically and with a mercury column. Pressure zero for both catheters was taken as the pressure in air. To check catheter drift, zero position was determined at the start of the study, and at the instant of withdrawal of the catheters from the patient. This latter level was used as zero pressure reference in the data analysis. Catheter drift was always directionally the same, of similar magnitude for both catheters, and never more than $3 \mathrm{mmHg}$. Airway pressure was measured by a water-filled transducer (Statham model P-23DB) connected by tubing to a mouthpiece. Simultaneous left ventricular, right ventricular, and airway pressures were recorded on magnetic tape (Hewlett Packard Instrumentation Recorder No. 3986A) along with the electrocardiogram, and a square wave marker used for synchronisation with the echocardiogram.

Two-dimensional phased-array echocardiograms (Varian V-3000 Phased Array Ultrasonograph) were recorded on magnetic video tape (IVC Model 870). Both longitudinal and cross-sectional views were obtained (the latter at the level of the papillary muscles).

EXPERIMENTAL PROCEDURE

After diagnostic cardiac catheterisation the study catheters were inserted, and with the patient supine, two-dimensional echocardiograms and simultaneous right and left ventricular pressures were recorded. Using a specially designed mouthpiece which allowed for sudden closure of the airway, the patients were asked to perform a Mueller manoeuvre, as previously instructed, by inspiring against the closed airway, resulting in a negative airway pressure of 40 to 80 $\mathrm{mmHg}$. Mueller manoeuvres were performed twice while recording a cross-sectional view, and twice with sagittal views. Pressures as well as echocardiograms were recorded continuously before, during, and with release of the Mueller manoeuvre. Measurements before and during the Mueller manoeuvre were made at functional residual capacity.

DATA ANALYSIS

Pressures

Haemodynamic data recorded on FM magnetic tape were either replayed into a strip-chart recorder and measured directly from analogue tracings or were digitised at $5 \mathrm{~ms}$ intervals (Nova 1220 computer) and the pressure data obtained from digitised records. A control beat was selected three to five beats before the Mueller manoeuvre. An early Mueller beat was defined as the first and second beat after inspiration, which corresponded to the time of maximal negative airway pressure. Simultaneous left ventricular and right ventricular pressures were noted at the time of minimal left ventricular pressure, at end-diastole (defined as the onset of the QRS complex), at mid-diastole before the onset of the "a" wave, and at the time of peak left ventricular systolic pressure.

\section{ECHOCARDIOGRAPHIC DATA}

The echocardiographic frames corresponding in time to end-diastole and end-systole were photographed with a Polaroid camera. These photographs were then enlarged by overhead projection. The endocardial contour was traced independently by two of us (JLW, LWE), and the septum and left ventricular free wall delineated. These images were also digitised using a light-pen system (Varian Instruments) to obtain the left ventricular cavity area. Adequate echocardiographic data were available during two Mueller manoeuvres in each of five patients and one Mueller manoeuvre in a sixth patient, making a total of 11 echocardiographic observations.

Changes in septal configuration during the Mueller manoeuvre were quantified by changes in the radius of curvature of the septum and compared with the radius of curvature of the left ventricular free wall, as previously described. ${ }^{17}$

The radius of curvature of a circle varies with a square root the area of that circle. To minimise the possibility that a change in the radius of curvature of a myocardial segment was the result of a change in ventricular cavity area, a normalised radius of curvature was also calculated. This was done by dividing the radius of curvature of a particular 
segment by the square root of the ventricular cavity area, as previously described. ${ }^{17}$

We compared the values measured during the control period with those measured during the early Mueller manoeuvre. All tracings and computations of radius of curvature and echocardiographic areas were done without knowledge of respiratory status or pressure data, with two investigators agreeing on each of the echocardiographic measurements. The results were expressed as mean \pm standard error of the mean. Statistical significance was tested using Student's $t$ test for paired or unpaired values as appropriate.

\section{Results}

(I) PRESSURES

In addition to the six patients in which adequate echocardiographic data could be obtained, pressures were recorded during Mueller manoeuvres in three patients resulting in a total of 14 pressure recordings. A representative example of the haemodynamic tracings during the Mueller manoeuvre is shown in Fig. 1. The tracings from top to bottom are: the left ventricular, right ventricular, and airway pressure, and the electrocardiogram with the square wave which marks the onset of the Mueller manoeuvre at the bottom. During control (pre-Mueller) the left ventricular diastolic pressure exceeded the right ventricular diastolic pressure at all times in all patients studied (Table). The control left ventricular enddiastolic pressure of $21.3 \pm 1.9$ is within the range of values obtained in our laboratory in normal patients, when the measurement is made after angiography.
Table Changes in haemodynamics with the Mueller manoeuvre

\begin{tabular}{|c|c|c|c|}
\hline & Control & $\begin{array}{l}\text { Early } \\
\text { Mueller }\end{array}$ & $P$ value \\
\hline $\begin{array}{l}\text { LV peak systolic } \\
\text { LV minimal diastolic }\end{array}$ & $133 \cdot 2 \pm 7 \cdot 2$ & $114 \cdot 2 \pm 7 \cdot 0$ & $<0.001$ \\
\hline $\begin{array}{l}\text { pressure }(\mathrm{mmHg}) \\
\text { LV pressure pre- }\end{array}$ & $8 \cdot 0 \pm 1 \cdot 3$ & $-22 \cdot 0 \pm 5 \cdot 3$ & $<0.001$ \\
\hline $\begin{array}{l}\text { "A" wave }(\mathrm{mmHg}) \\
\mathrm{LV} \text { end-diastolic }\end{array}$ & $12 \cdot 0 \pm 1 \cdot 2$ & $-18 \cdot 5 \pm 4 \cdot 9$ & $<0.001$ \\
\hline $\begin{array}{l}\text { pressure (mmHg) } \\
\text { RV peak systolic pressure }\end{array}$ & $\begin{array}{l}21 \cdot 3 \pm 1 \cdot 9 \\
26 \cdot 0 \pm 3 \cdot 2\end{array}$ & $\begin{array}{r}-12.3 \pm 5 \cdot 1 \\
-2 \cdot 6 \pm 6 \cdot 6\end{array}$ & $\begin{array}{l}<0.001 \\
<0.001\end{array}$ \\
\hline $\begin{array}{l}\text { RV minimal diastolic } \\
\text { pressure }(\mathrm{mmHg})\end{array}$ & $-1 \cdot 0 \pm 1 \cdot 0$ & $-29 \cdot 7 \pm 5 \cdot 5$ & $<0.005$ \\
\hline $\begin{array}{l}\text { RV pressure pre- } \\
\text { "A" wave (mmHg) } \\
\text { RV end-diastolic }\end{array}$ & $0.5 \pm 0.9$ & $-25 \cdot 9 \pm 5 \cdot 3$ & $<0.001$ \\
\hline $\begin{array}{l}\text { RV end-diastolic } \\
\text { pressure (mmHg) } \\
P_{1}(\mathrm{LV}-\mathrm{RV} \text { minimal diastolic }\end{array}$ & $2 \cdot 8 \pm 0 \cdot 8$ & $-21 \cdot 3 \pm 5 \cdot 2$ & $<0.005$ \\
\hline $\begin{array}{l}\text { pressure gradient } \\
\mathrm{P}_{2} \text { (LV-RV pre- " } \mathrm{A} \text { " wave }\end{array}$ & $9 \cdot 0 \pm 1 \cdot 7$ & $7 \cdot 8 \pm 1 \cdot 6$ & $<0.001$ \\
\hline pressure gradient) & $11 \cdot 5 \pm 1 \cdot 6$ & $7 \cdot 4 \pm 1 \cdot 5$ & $<0.001$ \\
\hline$P_{3}$ (LVEDP-RVEDP) & $18 \cdot 5 \pm 2 \cdot 1$ & $9 \cdot 4 \pm 1 \cdot 4$ & $<0.001$ \\
\hline$P_{\mathbf{4}}$ (LVS-RVS) & $109 \cdot 0 \pm 6 \cdot 0$ & $118 \cdot 8 \pm 9 \cdot 2$ & NS \\
\hline
\end{tabular}

Changes in haemodynamics with the Mueller manoeuvre. $n=14$; abbreviations: $L V$, left ventricle; $R V$, right ventricle; LVEDP, left ventricle end-diastolic pressure; RVEDP, right ventricular end-diastolic pressure.

Results expressed as mean \pm SEM

LVS, left ventricular peak systolic pressure; RVS, right ventricular peak systolic pressure.

The transseptal (LV-RV) pressure gradient varied from $(9 \cdot 0 \pm 1 \cdot 7 \mathrm{mmHg})$ at the time of minimal left ventricular pressure to $(18 \cdot 5 \pm 2 \cdot 1 \mathrm{mmHg})$ at enddiastole. With the onset of the Mueller manoeuvre the airway pressure immediately decreased to -40 to -80 $\mathrm{mmHg}$ (average $-58 \cdot 6 \pm 7 \cdot 65 \mathrm{mmHg}$ ). There was a

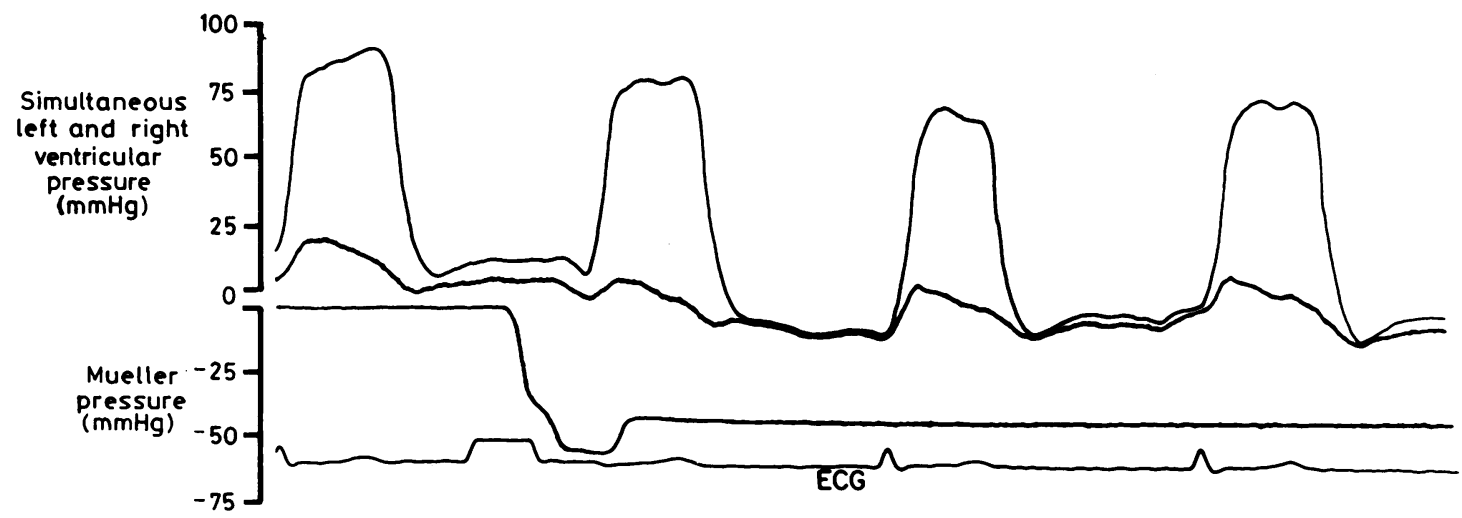

Fig. 1 Haemodynamic tracings of a Mueller manoeuvre from one patient. The tracings from top to bottom are the left ventricular, right ventricular, and airway pressures, and the electrocardiogram with a square wave marker which marks the onset of the Mueller manoeuvre. With the onset of the Mueller manoeuvre there is a sudden drop in the airway pressure and a concomitant decrease in the left-to-right diastolic transseptal pressure gradient. Even though the patient is maintaining a negative airway pressure, the diastolic left-to-right pressure gradient starts to return to baseline value. ECG, electrocardiogram. 
concomitant decrease in the transseptal pressure gradient throughout diastole (Table). The decrease in end-diastolic transseptal pressure gradient from control $(18 \cdot 5 \pm 2 \cdot 1 \mathrm{mmHg})$ to early Mueller $(9 \cdot 4 \pm 1 \cdot 4$ $\mathrm{mmHg}, \mathrm{p}<0.001)$ is illustrated in Fig. 2. Throughout diastole, however, right ventricular pressure did not at any time exceed left ventricular pressure. There was no significant change in the end-systolic transseptal pressure gradient $(109 \pm 6 \mathrm{mmHg}$ to $118 \cdot 8 \pm 9 \cdot 2$ $\mathrm{mmHg}$, NS).

\section{(II) RADIUS OF CURVATURE}

\section{(A) Control}

Although there was a small but significant difference between the absolute septal and free wall radius of curvature at end-diastole $(2 \cdot 64 \pm 0 \cdot 2$ vs $2 \cdot 20 \pm 0 \cdot 1 \mathrm{~cm}$, $\mathrm{p}<0.01$ ), there was no significant difference between the normalised radii of curvature $(0.72 \pm 0.06$ vs $0.62 \pm 0.04 \mathrm{~cm}, \mathrm{NS})$. During systole there was no significant difference between either the absolute radii of curvature $(1.65 \pm 0.2 \mathrm{vs} 1.55 \pm 0.1 \mathrm{~cm}, \mathrm{NS})$ or the normalised radii of curvature $(0.58 \pm 0.04$ vs $0.52 \pm 0.04 \mathrm{~cm}, \mathrm{NS})$.

\section{(B) Mueller manoeuvre}

Fig. 3 schematically illustrates the changes in septal configuration from control to the early Mueller manoeuvre. Note the increase in septal radius of curvature with the Mueller manoeuvre. The average radius of curvature at end-diastole during control was

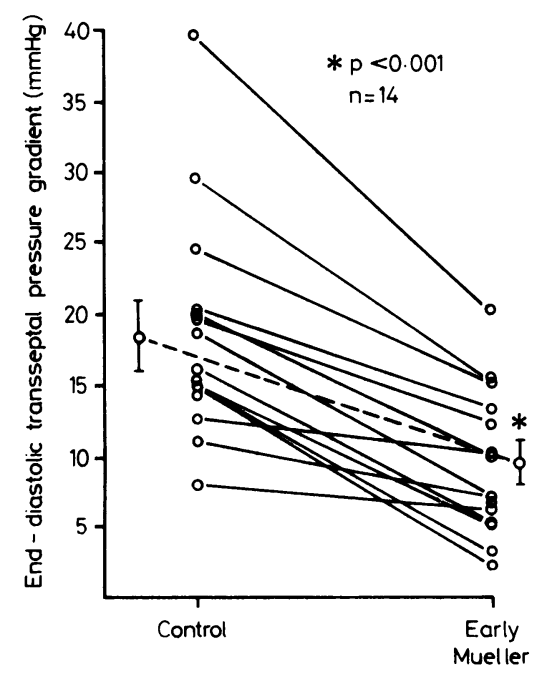

Fig. 2 Changes in end-diastolic transseptal pressure gradient from control to the early Mueller manoeuvre. The solid lines are individual Mueller manoeuvres in all patients studied, and the dashed line is the mean for the group.
$2.64 \pm 0.15 \mathrm{~cm}$. As shown in Fig. 4 (top panels), during the early Mueller manoeuvre the radius increased significantly to $4.21 \pm 0.34 \mathrm{~cm}(\mathrm{p}<0.001)$. It also increased significantly at end-systole $(1.65 \pm 0.51$ to $2.59 \pm 0.74 \mathrm{~cm}, \mathrm{p}<0.001$ ) with the Mueller manoeuvre. Simultaneous measurement of the left ventricular free wall radius of curvature shows that it did not change significantly either at end-diastole $(2 \cdot 2 \pm 0.42$ to $2 \cdot 1 \pm 0 \cdot 44$, NS) or end-systole $(1.55 \pm 0 \cdot 41$ to $1 \cdot 65 \pm 0 \cdot 57$, NS).

Left ventricular cavity area also decreased significantly on the cross-sectional view with the Mueller manoeuvre $\left(15 \cdot 2 \pm 0.9\right.$ to $11.0 \pm 0.8 \mathrm{~cm}^{2}$, $\mathrm{p}<0.001)$. Similar results were obtained for the normalised radii of curvature during both enddiastole and end-systole (Fig. 4, bottom panels).

Thus, the interventricular septum flattened towards the left ventricle during the early Mueller manoeuvre both at end-diastole and end-systole, in all subjects.

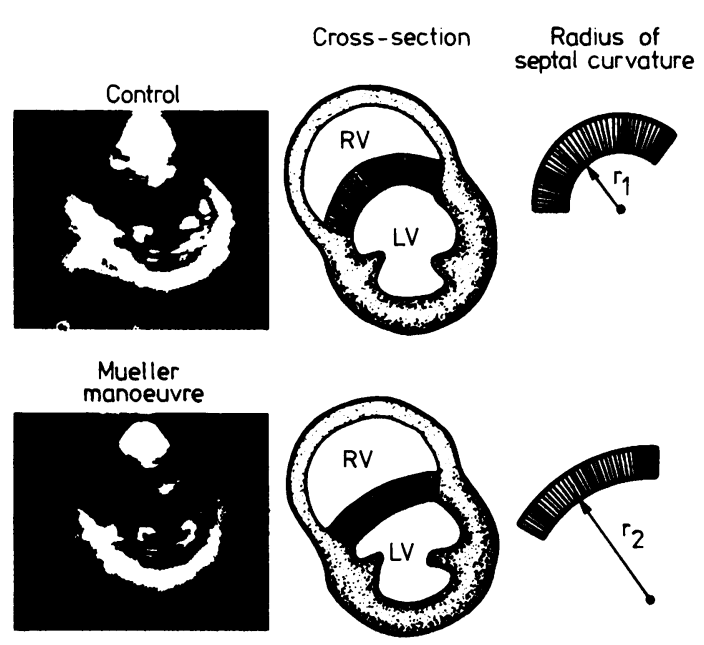

Fig. 3 Echocardiographic cross-section of the heart at enddiastole during a control period (top left panel) from one subject. The hatched areas on all diagrams (centre and right panels) represent the interventricular septum. The geometrically drawn figures to the right of each heart diagram show the radius of curvature of the interventricular septum during both respiratory periods. The more curved an object, the less the radius of curvature (top right panel); the flatter or less curved the object, the greater the radius of curvature (bottom right panel). All calculations that involved determination of the radius of curvature were done directly from $8 \times 10$ inch enlargements. $R V$, right ventricle; $L V$, left ventricle; $r_{1}$, radius of curvature during control; $r_{2}$, radius of curvature during control; $r_{2}$, radius of curvature during Mueller manouevre. (From Brinker et al. Leftward septal displacement during acute right ventricular loading in man. 1980; Circulation 61, 628. By permission of the American Heart Association. Inc.) 

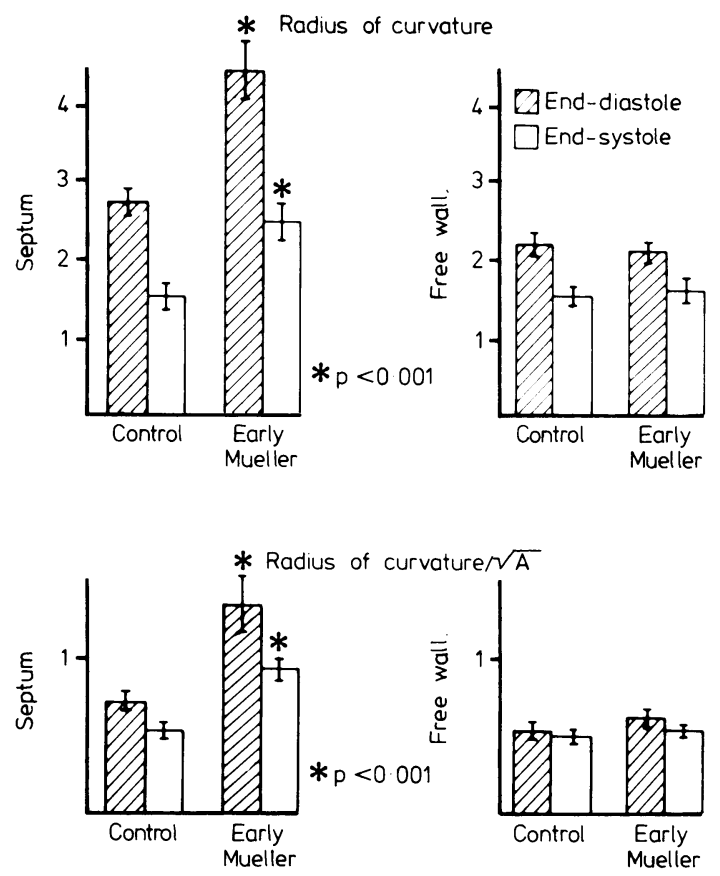

Fig. 4 Top panel; change in radius of curvature of interventricular septum and free wall from control to the early Mueller manoeuvre at end-diastole (cross hatched bars) and at end-systole (clear bars). Bottom panel: change in radius of curvature normalised to the square root of area $(\vee A)$.

\section{Discussion}

The key new finding that we have documented with this study is that the Mueller manoeuvre decreases the normal left to right diastolic transseptal pressure gradient. Accompanying this decreased gradient is a leftward septal displacement that does not require right ventricular diastolic pressure to exceed left ventricular diastolic pressure. Furthermore, septal displacement is maintained throughout systole despite the presence of a significant systolic transseptal pressure gradient.

Sharpey-Schafer ${ }^{18}$ has pointed out that with the onset of the Mueller manoeuvre there is an increase in the effective filling pressure of the right heart lasting two to three seconds, even though the negative intrathoracic pressure is maintained throughout the manoeuvre. As further evidence that the Mueller manoeuvre results in acute right ventricular loading, Brinker et al. ${ }^{17}$ showed that with the onset of the inspiratory effort, there is a significant increase in two-dimensional echocardiographic right ventricular diastolic dimension in both cross-sectional and longitudinal views.

We were initially concerned that the septal shift could in part be the result of rotation or translation of the heart during the Mueller manoeuvre. To address this question we recorded orthogonal views in all of our patients and, as in the earlier studies from our laboratory, ${ }^{17}$ observed septal displacement in both views. We reported the radius of curvature data only from the cross-sectional view. We measured the simultaneous changes in the radius of curvature of the left ventricular free wall as well as the septum, and showed that while the radius of curvature of the septum was increasing, the radius of curvature of the free wall did not change. These observations were further evidence that the septal shift was in fact occurring.

Previous work from this and other laboratories $^{78171920}$ has shown leftward septal displacement with acute right ventricular loading, but the mechanism underlying this septal shift has been unclear. Using sonomicrometer crystals to measure septal to lateral wall dimension, Bemis et al. ${ }^{7}$ showed that raising right ventricular end-diastolic pressure increasingly distorted left ventricular geometry by shifting the interventricular septum towards the left ventricle. They suggested that this increase in right ventricular pressure stiffens or buttresses the septum, thus leading to a decrease in left ventricular compliance. They did not, however, measure transseptal pressures. Using bead markers tracked by biplane cineangiograms, Stool et al. ${ }^{8}$ showed that increasing right ventricular pressure acutely decreased left ventricular volume and was associated with leftward septal shift, both at end-diastole and at end-systole. They suggested that bulging of the interventricular septum towards the left ventricular cavity could result in impaired left ventricular function. They too did not measure the changes in transseptal pressure gradients, or correlate these changes with changes in septal geometry.

There are several possible mechanisms to explain leftward septal displacement during right ventricular loading. The first is that the normal septal position in the unstressed heart is actually more towards the left ventricle, that is, flatter, but that it is held in its usual concave position by the normal left-to-right pressure gradient. Acute loading of the right ventricle might then result in a decrease in this gradient and cause the septum to shift leftwards. Recently, in eight conscious dogs, Olsen et al., ${ }^{19}$ using ultrasonic dimension transducers and micromanometer catheters, showed that left ventricular geometry was significantly distorted by septal shifting during pulmonary arterial occlusion. This diastolic septal shift seemed to be related to the transseptal pressure gradient and did not require right ventricular pressure to exceed left ventricular diastolic pressure (personal communication). 
The second possible mechansim relates to the possibility that the diastolic septal area subtended by the right ventricle exceeds that subtended by the left ventricle. Thus, as the diastolic transseptal pressure gradient decreases and right ventricular dimension changes, there could be a net right-to-left force on the septum despite a left-to-right pressure gradient.

A third possible explanation, which may also explain why the interventricular septum remains shifted during systole, is that acute right ventricular loading, by changing the size and/or geometry of the right ventricle, alters the local balance of forces at the right ventricular-septal junctions, thereby not only influencing septal position, but also altering the internal stresses within the septum. In a normally loaded heart, Pao et al. ${ }^{21}$ have shown that there may be considerable regional variations in wall stresses. In the septum, compressive stresses may occur on the endocardial left ventricular surface. When the septum is displaced leftward during the Mueller manoeuvre, compressive stresses could be produced on the right ventricular side of the septum which would then help maintain its displaced position despite a very large left-to-right systolic pressure gradient.

In conclusion, we have shown that the observed septal shift produced by acute right ventricular loading with the Mueller manoeuvre is accompanied by a decrease in the diastolic transseptal pressure gradient, but does not require the right ventricular diastolic pressure to exceed the left ventricular diastolic pressure. Furthermore, this septal shift persists during systole for two to three beats despite the large left ventricular to right ventricular systolic pressure gradient. This suggests that there are factors not reflected in the transseptal pressure gradient which can lead to significant changes in septal geometry and hence regional left ventricular geometry. Further studies are needed to delineate these factors, and their influence on left ventricular function.

\section{References}

1 Ludbrook PA, Byrne JD, McKnight RC. Influence of right ventricular hemodynamics on left ventricular diastolic pressure-volume relations in man. Circulation 1979; 59: 21-31.

2 Brodie BR, Grossman W, Mann T, McLaurin LP. Effects of sodium nitroprusside on left ventricular diastolic pressure-volume relations. $\mathcal{F}$ Clin Invest 1977; 59: 59-68.

3 Alderman El, Glantz SA. Acute hemodynamic interventions shift the diastolic pressure-volume curve in man. Circulation 1976; 54: 662-71.

4 Taylor RR, Covell JW, Sonnenblick EH, Ross J Jr. Dependence of ventricular distensibility on filling of the opposite ventricle. Am $\mathcal{F}$ Physiol 1967; 213: 711-8.
5 Laks MM, Garner D, Swan HJC. Volumes and compliances measured simultaneously in the right and left ventricles of the dog. Circ Res 1967; 20: 565-9.

6 Moulopoulos SD, Sarcas A, Stamatelopoulos S, Arealis E. Left ventricular performance during by-pass or distension of the right ventricle. Circ Res 1965; 17: 484-91.

7 Bemis CE, Serur JR, Borkenhagen D, Sonnenblick EH, Urschel $\mathrm{CW}$. Influence of right ventricular filling pressure on left ventricular pressure and dimension. Circ Res 1974; 34: 498-504.

8 Stool EW, Mullins CB, Leshin SJ, Mitchell JH. Dimensional changes of the left ventricle during acute pulmonary arterial hypertension in dogs. Am $\mathcal{f}$ Cardiol 1974; 33: 868-75.

9 Glantz SA, Parmley WW. Factors which affect the diastolic pressure-volume curve. Circ Res 1978; 42: 171-80.

10 Grossman W, McLaurin LP. Diastolic properties of the left ventricle. Ann Intern Med 1976; 84: 316-26.

11 Janicki JS, Weber KT. The pericardium and ventricular interaction, distensibility, and function. Am $\mathcal{F}$ Physiol 1980; 238: H494-H503.

12 Berglund E, Sarnoff SJ, Isaacs JP. Role of the pericardium in regulation of cardiovascular hemodynamics. Circ Res 1955; 3: 133-9.

13 Glantz SA, Misbach GA, Moores WY, et al. The pericardium substantially affects the left ventricular diastolic pressure-volume relationship in the dog. Circ Res 1978: 42: 433-41.

14 Ross J Jr. Editorial: Acute displacement of the diastolic pressure-volume curve of the left ventricle: role of the pericardium and the right ventricle. Circulation 1979; 59: 32-7.

15 Shabetai R, Mangiardi L, Bhargava V, Ross J Jr, Higgins CB. The pericardium and cardiac function. Prog Cardiovasc Dis 1979; 22: 107-34.

16 Mirsky I, Rankin JS. The effects of geometry, elasticity and external pressures on the diastolic pressure-volume and stiffness-stress relations. Circ Res 1979; 44: 601-11.

17 Brinker JA, Weiss JL, Lappé DL, et al. Leftward septal displacement during right ventricular loading in man. Circulation 1980; 61: 626-33.

18 Sharpey-Schafer EP. Effect of respiratory acts on the circulation. In: Hamilton WF, Dow P, eds. Handbook of physiology. Section 2. Washington DC: American Physiological Society, 1965: 1875-86.

19 Olsen CO, VanTrigt P, Pellom GL, et al. Determinants of interventricular septal shifting in conscious dogs (abstract). Circulation 1980; 62, suppl III: 69.

20 Scharf SM, Brown R, Saunders N, Green LH. Effects of normal and loaded spontaneous inspiration on cardiovascular function. F Appl Physiol 1979; 47: 582-90.

21 Pao YC, Robb RA, Ritman EL. Plane-strain finiteelement analysis of reconstructed diastolic left ventricle cross section. Ann Biomed Eng 1976; 4: 232-49.

Requests for reprints to Dr Pablo A Guzman, Blalock 106-A, The Johns Hopkins Hospital, $600 \mathrm{~N}$ Wolfe Street, Baltimore, Maryland 21205, USA. 